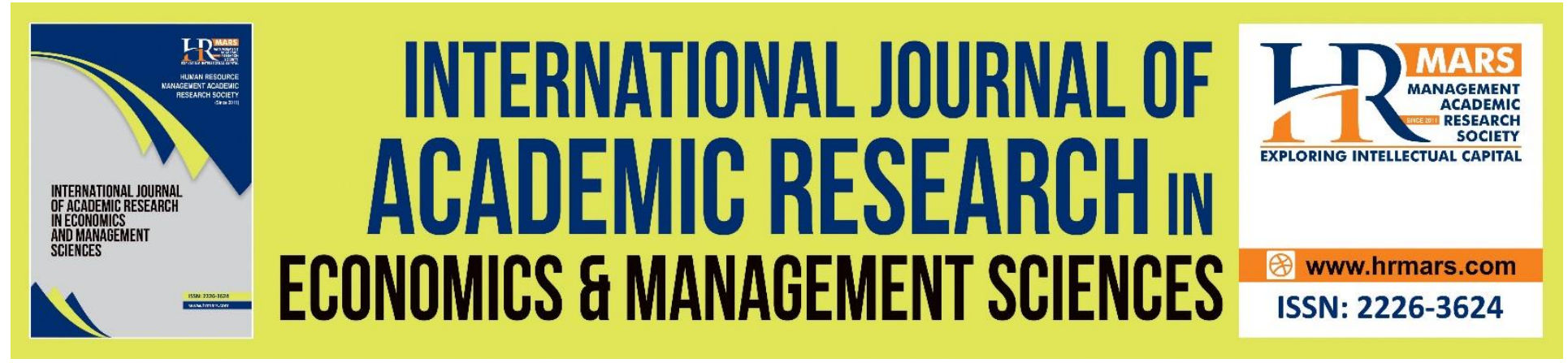

\title{
Urban Sustainability and Ecological Footprint towards Health Expenditure: A Conceptual Paper
}

\author{
Nor Aziah Abd Kadir, Adibah Hussin, Fazreena Mansor, Nur Fakhzan Marwan \\ \& Rosmah Nizam
}

To Link this Article: http://dx.doi.org/10.6007/IJAREMS/v10-i4/11386

DOI:10.6007/IJAREMS/v10-i4/11386

Received: 01 August 2021, Revised: 09 September 2021, Accepted: 26 September 2021

Published Online: 12 October 2021

In-Text Citation: (Kadir et al., 2021)

To Cite this Article: Kadir, N. A. A., Hussin, A., Mansor, F., Marwan, N. F., \& Nizam, R. (2021). Urban Sustainability and Ecological Footprint towards Health Expenditure: A Conceptual Paper. International Journal of Academic Research in Economics and Management and Sciences, 10(4), 1-17.

Copyright: (C) 2021 The Author(s)

Published by Human Resource Management Academic Research Society (www.hrmars.com)

This article is published under the Creative Commons Attribution (CC BY 4.0) license. Anyone may reproduce, distribute, translate and create derivative works of this article (for both commercial and non-commercial purposes), subject to full attribution to the original publication and authors. The full terms of this license may be seen at: http://creativecommons.org/licences/by/4.0/legalcode

Vol. 10, No. 4, 2021, Pg. 1 - 17

http://hrmars.com/index.php/pages/detail/IJAREMS

JOURNAL HOMEPAGE

Full Terms \& Conditions of access and use can be found at http://hrmars.com/index.php/pages/detail/publication-ethics 


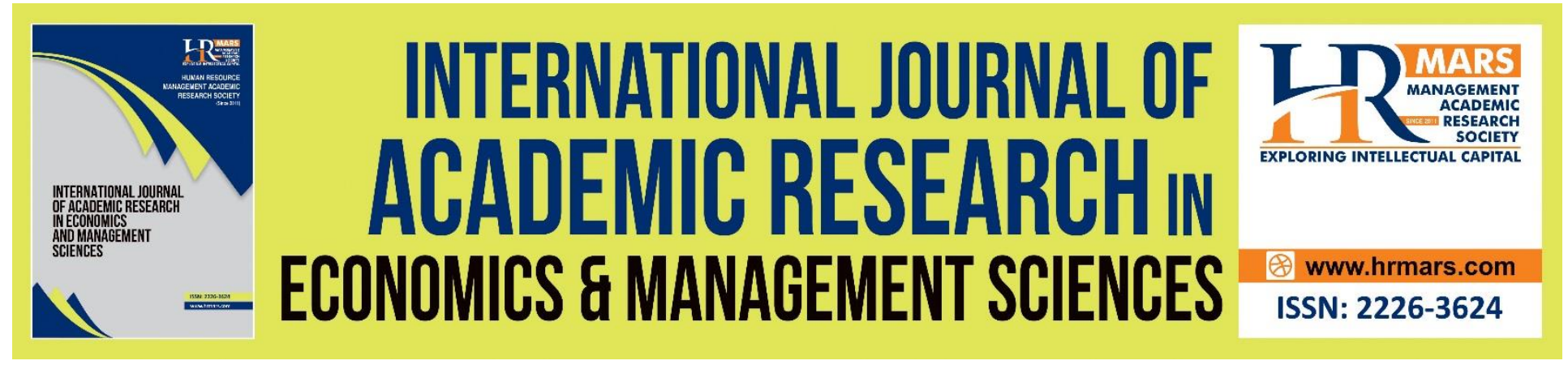

\title{
Urban Sustainability and Ecological Footprint towards Health Expenditure: A Conceptual Paper
}

\author{
Nor Aziah Abd Kadir ${ }^{1}$, Adibah Hussin², Fazreena Mansor ${ }^{3}$, Nur \\ Fakhzan Marwan ${ }^{4}$ \& Rosmah Nizam ${ }^{5}$ \\ 1,3,4 Faculty of Business Management, Universiti Teknologi MARA Cawangan Pahang, Raub \\ Campus 27600 Raub, Pahang, Malaysia, 2,5 Faculty of Business Management, Universiti Teknologi \\ MARA Cawangan Pahang, Jengka Campus 26400 Bandar Tun Abdul Razak Jengka, Pahang, \\ Malaysia \\ Corresponding Author's Email: aziahkadir@uitm.edu.my
}

\begin{abstract}
Urban Sustainability is one of the most important agendas for a country to focus on as it makes the society and communities live in balance and defensible. The pleasant surrounding will create better production and economic growth. Most of the researchers found that the urban population will increase environmental degradation. It is involved the destruction of the environment and is included as one of the ecological footprints produced by humanity. The ecological footprint will increase and affect the health level of the nation. People may suffer skin irritation because of air pollution, diarrhea from water pollution, and others. Urbanization itself may directly influence health expenditure as it refers to the demographic transition from rural to urban. Since the population of urban is increasing, their health spending also increases. This paper will provide a conceptual framework on the relationship between urban sustainability and ecological footprints on health expenditure which can help spread the importance of urbanization policy to reduce the ecological footprint and spending. Therefore, the government may focus on other types of expenditure for the country's development.
\end{abstract}

Keywords: Ecological Footprint, Health Expenditure, Urban Sustainability

\section{Introduction}

Health is significant to measure the quality of human capital. Good health will support humankind to increase the level of production and contribute to economic growth. Few factors were identified as the cause of the people's health condition, such as eating habits, lifestyle, cleanliness, socioeconomic position, education, and ecological issues. The ecological footprint has been used recently in many studies to measure pollution as it comprehensively includes a broad range of air, water, and soil pollutants. Precisely, ecological footprint tracks the use of productive surface areas, including cropland, grazing land, fishing grounds, built-up land, forest area, and carbon demand on land. 
Previously, most of the research analyzed the connection between CO2 emissions, GDP, and health spending. Several scholars have followed the Environmental Kuznets Curve (EKC), which studies the relationship between economic growth and environmental quality (Cai, Sam \& Chang, 2018; Pata UK, (2018). Then, that second analysis focused on the link between health spending and GDP. The economists calculated the elasticity of income to determine the nature of health care services for that country. Then, they researched how to predict health care demand among people and how to distribute health care resources among communities based on the calculated income elasticity. Finally, the third analysis focused on the link between $\mathrm{CO} 2$ emissions and health care costs. Many investigations have focused on one-way causality from $\mathrm{CO} 2$ emissions to health spending and have discovered favorable links (Wang et al., 2019). Previous research has recommended methods to support pollution reduction and environmental preservation, such as investing in low-carbon development and improving climate resilience, emphasizing increasing investments in the healthcare sector. According to Geng et al (2019), many researchers have conducted an empirical study of the long-term effect of air pollution at the national level. Air pollution can increase health care spending as it defects the socioeconomic patterns and increased demand for health care. According to the United Nations Environment Program, the financial cost of outdoor environmental pollution in developing nations amounts to around $5 \%$ of their GDP (United Nations Environment Program, 2016). The UNEP's empirical models captured the connection of health and energy consumption during the manufacturing, commerce, and urbanization processes.

In place of that, City \& Assessment (2010) wrote an article related to urbanization and health. They mentioned that more than $50 \%$ of the world's population lives in an urban area. By forecast, in 2050,70\% of the world's population will be living in towns and cities because urban living offers many opportunities, including better-paid occupation, higher level of education, high standard of lifestyle, better potential access to better health care, and many more. However, nowadays, the urban's environment turns to disaster as it can concentrate health threats and introduce new hazards.

The offer from urban such as a rapid increase in industrialization and production activities will attract rural people to urban. The increase in an urban population will increase energy use, depletion of resources, and demand for high ecological and environmental services. This situation, later on, will have a destructive impact on the resources as it may deplete and potentially create high emissions of carbon (Wei et al., 2018). According to Zhang \& Ju (2011), the amount of $\mathrm{CO} 2$ emissions from China's metropolitan regions accounted for around 65 percent of the country's overall emissions. At this point, the environment's deteriorating quality is slowly but gradually posing a significant threat to healthy living by increasing the danger of greenhouse gas emissions and climate change. Increasing the greenhouse effect and hence global warming will result in a rise in cardiovascular and cerebrovascular illnesses (Abdullah, Azam \& Zakariya, 2016) and injury incidents such as causing heatwaves (Watts et al., 2019), floods (Mallett \& Etzel, 2018), cyclones (Shultz et al., 2017), and droughts (Berman et al., 2017).

Poor environmental quality is an inevitable presence in many developing countries and serves as the main reason for numerous health destruction, pollution, and increasing chances of getting 
low health conditions. Insufficient access to clean water, for instance, will result in diarrhea (Hardy et al., 2019), typhoid fever (Stanaway et al., 2017), and cholera (Zerbo et al., 2020). Additionally, deforestation may also produce another positive condition for the dispersion of vectors such as malaria, and others, and thus, will cause increases in health spending (Ramírezchaves et al., 2020). Climate change poses direct and grave dangers not just to our community now but also to future generations. To the best of our knowledge, without proper mitigation and adaptation, all the issues mentioned earlier will ultimately lead to any possibility of health care cost increases. Being exposed to air pollution in the long run, people may suffer from respiratory systems, infant mortality, and life expectancy (Chen et al., 2013) or even affect human's sleeping problems (Heyes \& Zhu, 2019). All these negative impacts are consequently affecting economic costs. Thus, the higher the air pollution will deteriorate financial cost.

Several local researchers have study and found the factors concerning the economic determinants of health expenditure (Boachie \& Ramu, 2017; Eneji et al., 2013; Kim \& Lane, 2013; Rahman, 2011), but very few of them delve into the influence of ecological footprint on health expenditure because of limitation of local data availability. Thus, this study is a pioneer attempt to fill the gap identified in the existing literature concerning the relationship between urbanization and ecological footprint towards health expenditure. This research gap rationalized the need for this current study. The finding may spread the knowledge on the importance of planned urbanization and built environment to reduce the ecological footprint and government expenditure. Moreover, it is imperative to increase the knowledge and awareness among people to reduce the energy used, minimize pollution, and wisely manage solid waste. These may prevent them from being exposed to health problems and reduce their spending on healthcare. The government may use or channel their health expenditure to the other types of spending for its development.

However, this study only looked at two factors that influence health spending, i.e., ecological footprint and urbanization, whereas other significant predictors were ignored. The study will discuss the topic based on seven sections. Section one is an introduction, section two consists of the proposed conceptual model, section three of literature present a review of theory underpinning, section four development of research proposition shows the result, section five is a conclusion, section six is a theoretical and contextual contribution, and the final section presents the suggestion for future research.

\section{Proposed Conceptual Model}

The conceptual model proposes a relationship between urbanization, ecological footprint, and health expenditure. Health expenditure is a dependent variable and ecological footprint and urbanization are the independent variables. 


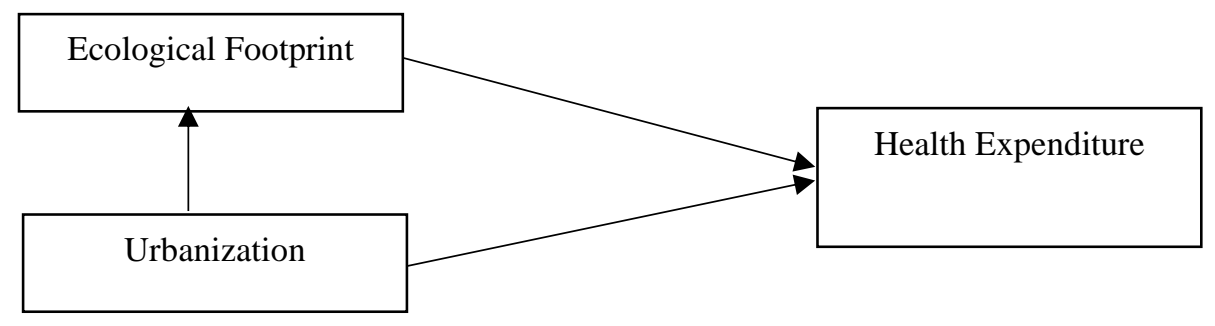

Figure 1: Health Expenditure Conceptual Model

The health expenditure can be measured using total health expenditure per capita. The measurement of health expenditure was performed by adding up all the public and private health expenditures performed by a country. Two independent variables were examined as predictors of health expenditure. These variables are ecological footprint and urbanization. The study expects that there is a positive relationship between the independent variables and dependent variables. Fattahi (2015); Yin et al (2020) found that urbanization directly influences health expenditure. The increment of the total population of the area and increase the need for healthcare consumption. While the ecological footprint is believed to correlate positively to health expenditure, it is proven and supported by Gillani et al (2021). The independent variables are also expected to give a one-way causal relationship. It is expected that urbanization will cause the ecological footprint to increase. Lu \& Chen (2017) empirically proved that urbanization is an essential determinant of ecological footprint. Urbanization increases ecological footprint, indicating that the correlation between the variables exists and that urbanization has a causal relationship with the ecological footprint.

\section{Theoretical Underpinning Health Expenditure}

World Health Organization (WHO) provides The Global Health Expenditure Database (GHED) internationally with comparable data on health spending close to 190 countries from 2000 2021. From that database, the expenditure on health shows an incremental trend for many countries. The amount of health expenditure is directly related to its income. Although the ratio of expenditure on health to total spending in the economy fluctuates over time, their relationship remains WHO defines health expenditure as an expenditure for health facilities, family planning activities, nourishment activities, and emergency relief targeted for health. However, it does not include the supply of drinking water and sanitation (https://apps.who.int/nha/database). Health spending is an essential element of healthcare systems. It also corresponds to the 3rd Sustainable Development Goals (SDG), which ensure people live a healthy life. If a country reports a significant incidence of disease, illness, and poverty, it is difficult for them to attain sustainable development goals. Development is measured by economic performance and includes health, education, and social structure. Thus, health expenditure will bring a more significant health opportunity, which can help enhance human capital, increase productivity, and stimulate economic performance. Therefore, assessing the phenomena of healthcare spending in a country should be given serious attention. 
Various studies have used different variables to measure health expenditure. Zaidi \& Saidi (2018) used to measure the health expenditure in the form of total health expenditure for a country. This expenditure covers all spending for healthcare, including providing health services, family planning, nutrition, and emergency support for all health-related activities. On the other hand, some others (Alimi, Ajide \& Isola, 2020; Rahman, Khanam \& Rahman, 2019) divided it into public and private expenditures. Public health expenditure consists of all spending of government budgets on public health services. Public financing in health amenities and capital allocations to the private sector for hospital building and equipment are examples of public capital formation in health (Huber \& Oroz, 2003). At the same time, the private expenditure includes the health expenditure of individual or private agencies, such as the payment for personal life insurance. However, public and private health expenditures have different impacts on the health status of a country. Therefore, most studies use this public and private expenditure individually.

There is no straightforward theory discussed by scholars to explain the factor that influences health expenditure in a certain country, but certain broad assumptions for the empirical model may be stated. Researchers believe that any economy's overall health expenditure reflects the demand for health care. Expenditure in this sector rises in tandem with GDP, population aging, pollution, and energy intensity (Apergis, Bhattacharya \& Hadhri, 2021). Most importantly and sadly, the coronavirus 2019 outbreak possess an unforeseen challenge to global healthcare systems since mid-2019. The value of health infrastructure has risen dramatically in the postCOVID era. The nation struggles to provide the best national healthcare capacity, an advanced ICU, and other public health infrastructure levels. Recent research on the new coronavirus (COVID-19) has underlined the importance of boosting health spending even at the expense of defense spending (Lebni et al., 2020).

\section{Ecological Footprint}

With the high level of human development, countries will spend more on health to improve their safety and well-being. The increase in spending is due to the threat of an ecological footprint that will harm human health and lower productivity (Lenzen et al., 2020). The contribution of environmental policies in reducing pollutions has been one of the major concerns of a nation where it can be a holistic measure of human pressure on the environment (Arshad \& Khan, 2021). Recently many scholars used the ecological footprint as a variable in their study to achieve the Sustainable Development Goals (SDG) of ensuring people are getting clean water, affordable and clean energy, and climate action. The phenomena of ecological footprint have become more skewed and important (Qaiser et al., 2021). With this variable, they manage to explain the related issues of good health and well-being for a nation.

The ecological footprint measures the area of biologically productive land and water required for an individual or activity to produce all the resources it consumes and absorb the waste it generates, using prevailing technology and resource management practices (Li, Hui, Leung, Li \& $\mathrm{Xu}, 2010)$. The ecological footprint is defined as the total land and water area required to support a population with a specified standard of living and technology while also grasping all wastes and emissions for an indeterminate time.

According to the Global Footprint Network 2021, it shows an increasing trend of the data of world ecological footprint by land type for more than 200 countries between the years 1961 and 2017. 
This data consists of carbon, fishing grounds, cropland, built-up land, forest products, and grazing land. Thus, EFP has established itself as an essential environmental indicator. The footprint is a good indicator of a population's demand for resources compared to the available supply of nature, and it's becoming more helpful at any level of a country. It not only evaluates the longterm viability of present human activities but also supports public consciousness and determination. Therefore, this study on ecological footprint toward economic prosperity and environmental sustainability is essential since most countries nowadays face ecological deficits; footprint is more prominent than its biocapacity, where $85 \%$ of the world population lives in an ecological deficit country.

Furthermore, almost $70 \%$ of the world's population lives on less than average income, allowing them to maintain and support themselves through resource abuse. Due to the tightening of ecological constraints, a country's ability to achieve sustainable development is linked to its ability to stay within these limits (GFN, 2018). However, to compensate for their non-natural capitals, many nations turn to trade, resource exploitation, or emit more carbon into the atmosphere than their national forests can absorb, surpassing these limitations, implying unsustainable resource usage. Unsustainable natural resource usage impacts a country's biocapacity (the ability of natural resources to regenerate themselves), raises the ecological footprint and leads to an ecological deficit. Furthermore, natural resource exploitation is growing due to increased economic expansion, posing a potential environmental danger (Danish et al., 2019).

\section{Urban Sustainability}

Urban and sustainability are two dependent processes to which the notions have been embedded in most academic terms. The rise of the terms coined the new phrase "urban sustainability" or "sustainable urbanization" and used it as a catch-all term for economically, socially, and environmentally urban systems. Numerous studies have analyzed the nexus between urbanization and sustainability (Zeng et al., 2016; Rogers et al., 2012).

Huang, Wu \& Yan (2015) define urban sustainability as the process of improving human wellbeing through actions in the environmental activities, economic allocation of resources and efficiency, and social well-being and health dimensions. It has proven that urban sustainability is a challenging task for every individual as well as a nation. As far as it is concerned, some researchers regard urbanization as the primary key towards regional and global sustainability, while few others with their adverse opinions believe that urban sustainability seems to be another oxymoron (Wu, 2010).

With the attendant need to stabilize the global climate, urbanization is one of the most destructive forces that spur negative impact on the environment. In fact, urbanization has long been deemed as a problem for the rich and the poor. Depending on social modernization and economic condition, urbanization may be a factor in long-term growth if it is well-planned and manageable, allowing for expanded productivity and the development of new models. The contribution can achieve more than $80 \%$ of global GDP. In terms of GDP rankings, the wealthiest city in the world today is Tokyo, Japan. Tokyo contributed USD 1,520 billion to the GDP, followed 
by New York, USA of USD 1,210 billion (UN Habitat, 2020). The increment in population may also compound an adverse condition by experiencing growing inequality, debility, and environmental degradation. According to UN-Habitat, cities utilize 78 percent of the world's energy and generate more than 60 percent of gas emissions, and because of that, the population is susceptible to the consequences of climate change (UN Habitat, 2020). On the other hand, higher economic growth leads to a higher rate of urbanization. Urbanization increases the need for transportation and industrialization, as well as energy consumption, particularly fossil fuel usage, and the ECF. The rapid rate of urbanization generates revenue at the expense of natural resource exploitation and public health. Aside from that, urbanization creates positive externalities, economies of scale, and the provision of public services. Urbanization improves the purchasing power of city dwellers, which may shift demand toward clean energy use, lowering ecological footprint (Danish \& Wang, 2019).

\section{Development of Research Propositions Ecological Footprint and Health Expenditure}

Previously, researchers used carbon dioxide (CO2), sulfur dioxide (SO2), and nitrogen dioxide (NO2) as a substitute for environmental degradation. $\mathrm{CO} 2$ and $\mathrm{SO} 2$ are the most researched pollutants in economics. $\mathrm{CO} 2$ is the primary cause of global warming and the most widely used gas by businesses and consumers. This gas emission is non-point pollution, which needs exceptional control. SO2 is a pollutant that is mostly caused by industry and is a more localized pollutant. Given its effects on health, acid rain, and other factors, it is one of the most harmful pollutants. While NO2, a by-product of burning produced by indoor gas appliances like cooking stoves, is linked to respiratory symptoms in those with disruptive airway disease. Yazdi \& Tahmasebi (2014) used CO2 and SO2 to investigate Iran's environmental condition and public health spending. They found that $\mathrm{CO} 2$ and $\mathrm{SO} 2$ are significant and positively related to health expenditure. Later, Abdullah et al. (2016) added the NO2 as a new variable for environmental quality. They tested the variables using the ARDL approach, and the result revealed was also significant and positive with public health expenditure. Moreover, Fattahi (2015); Apergis et al (2021) used panel data analysis to examine the cross-country comparison across several income groups. They found that $\mathrm{CO} 2$ is completely correlated to health expenditure.

Yahya et al (2016) tested new variables of carbon monoxide, CO2, nitrous oxide, and income per capita on health expenditures in the long run. The result shows a positive relationship with health expenditure. However, in the short run, nitrous oxide and sulfur dioxide had little effect on per capita health costs in developing nations. They concluded that the Green House Gas (GHG) emissions were the main predictor of health expenditure. The gases were deteriorating the environment and harmed health care expenditure. Ibukun and Osinubi (2020) measure the effect of environmental quality, carbon dioxide, nitrous oxide, and methane emissions on health expenditure. The study's findings show that economic growth has a positive and substantial influence on health spending and a positive and significant link between poor environmental quality and health spending. The empirical findings of this study show that, among the three proxies of ecological quality, carbon dioxide emissions had the most significant impact on healthcare spending, although economic growth raised health spending considerably across the five African areas (North Africa, East Africa, Central Africa, West Africa, and Southern Africa). 
Instead of carbon emission, the improper handling of waste from electrical and electronic equipment can also cause severe environmental pollution and affect public health. Vaccari et al (2019) argued that environmental degradation could be affected by an increase in the use of informal Waste Electrical and Electronic Equipment (WEEE) treatment services. The waste can create pollution and spread the unhealthy environment. It may reduce human health. Open burning and open dumping are the worst practices used by countries that lack adequate regulation and waste management services. As the environmental pollution increases in a country, they found that the health condition of the people is getting worse due to many health issues arising to the government's knowledge. The government has taken many methods to control the health problems and affected the government spending on healthcare. As a result, it is true that rising environmental pollution invariably results in higher healthcare costs.

Mehrara, Sharzei, and Mohaghegh (2011) backed up the current stance by stating that there was a close link between health spending and environmental quality. Using panel cointegration tests, error correction models, and Ordinary Least Square (OLS) to evaluate the long-term equilibrium as well as the short-term effect, the study found evidence of a direct relationship between environmental quality and health spending in both the short and long run.

Shen, Wang \& Shen (2021) investigated the presence of a threshold impact of industrial air pollution on medical costs in China using the fixed-effect model, random-effect model, and PTRM. There is a non-linear threshold effect between the two in western China. Before the critical value, air pollution lowers healthcare costs; but beyond the crucial deal. However, the increased value is insufficient to compensate for the adverse effects of pollution. The findings show that severe pollution increases medical spending in both the eastern and central areas, with the central region having a higher impact on air pollution than the east region.

Similarly, with other proxies of environmental degradations, ecological footprint also may harm society. Recently, Gillani et al. (2021) used ecological footprint to measure the relationship toward health outcomes. The ecological footprint increases population mortality by breaking the ecosystem, particularly among children under the age of five and infants.

All these studies have little to say about ecological footprints or pollution and health consequences, including illnesses, sickness, and mortality. However, there was no research in the context of health spending. As a result, the current study postulated the following to explain the link in health spending as a dependent variable:

Proposition 1: Ecological footprint influences health expenditure.

\section{Urbanization and Health Expenditure}

Urbanization issues are becoming one of the crucial factors and challenges to the government regarding socioeconomic accomplishment. According to WHO, unplanned urbanization may negatively impact the environment, water system, violence, and noncommunicable diseases such as cancers, diabetes, and others (World Health Organization, 2011). These diseases show 
that urbanization and health outcomes are interrelated to each other in the developing world and may increase the health expenditure for a nation (Çetin \& Bakirtaş, 2019).

Fattahi (2015); Kouassi et al (2018); Magazzino et al (2020); Magazzino \& Mele (2012) similarly did research testing on different nations and populations and used other methods. The conclusion also denotes that urbanization was significantly and positively related to public health expenditure. Likewise, Shi, Smit, and Luck (2020) expressed that rapidly increased urbanization would also lead to high health expenditure by increasing the total treatment cost and out-ofpocket cost. Although urbanization hampered some excellent opportunities for economic development, it could also bring significant health costs by putting the lives of vulnerable populations at serious risk. For instance, a study by Patil (2014) demonstrated the major health issues are expected to arise from the urbanization process and simultaneously induce health expenditure, particularly among the urban poor.

As been discussed, previous studies have found the dynamic linkages between urbanization and health expenditure (see, for example, Gbesemete \& Gerdtham, 1992; Fattahi, 2015; Kouassi et al., 2018; Magazzino et al., 2020; Magazzino \& Mele, 2012; Shi et al., 2020; Patil, 2014). Conversely, some researchers such as Pan and Liu (2012); Boachie et al (2014) postulated that urbanization and health expenditure are negatively associated. Although previous literature has offered mixed results, this study proposed that urbanization is positively related to health expenditure. Therefore, this paper anticipates that:

Proposition 2: Urbanization influences health expenditure.

\section{Urbanization and Ecological Footprint}

Kissinger, Sussman, Moore \& Rees (2013) used community solid waste composition consisting of energy use and carbon dioxide emissions data to proxy material consumption. They found that these material consumptions may give critical issues to the urban population. This is because the increment in population will increase global resource depletion and energy used. Thus, provide an impact on the ecosystem. However, in this study, the data was limited, and they claimed that some materials like textiles and aluminium have high ecological footprints but make up relatively more minor proportions of urban waste streams than products like paper and diapers. This is because the data for that proxy is also limited to some aspects of pollution only.

Nathaniel \& Khan (2020) has denoted ecological footprint as a measure of environmental degradation. They reveal that urbanization increases the ecological footprint. They used the causality test and confirmed that urbanization has one-way directional causality to the ecological footprint, which causes an increase in the ecological footprint.

Indeed, a vast corpus of research is investing in the positive relationship between urbanization and ecological footprint. The findings found by Ahmed et al (2020) on G7 countries were pretty much in the same vein revealed that urbanization is positively associated with the ecological footprint. In fact, many studies attempted to study the relationship between these two variables with varying results. For instance, Khan, Hou, Le \& Ali (2021) investigated the nexus between 
urbanization and the ecological footprint in the top ten manufacturing countries using obtained data from 1970 to 2016. The results implied that urbanization deteriorates environmental quality, which ultimately stimulates the ecological footprint. Al-Mulali and Ozturk (2015) disclose a significant effect of urbanization on the ecological footprint in 14 MENA (the Middle East and North Africa) regions. Mahmood et al (2020) examine the relationship between urban population and ecological footprint in the context of Saudi Arabia. The result indicated that the urban population enhanced the level of environmental degradation in the long run.

In contrast, Yang, Usman \& Jahanger (2021) investigate the effect of urbanization on the ecological footprint in the ten countries with the highest healthcare spending. The data was obtained from 1995-2018 by using the Stochastic Impacts by Regression on the Population, Affluence, and Technology (STIRPAT) framework, and the results indicated that urbanization has lagged negative impact on ecological footprint. Additionally, studies like those of Lee \& Lin (2020), Rashid et al. (2018), Charfeddine and Mrabet (2017) implied that urbanization imposed a negative impact on ecological footprint due to several factors.

Summing up, as the previous literature has presented diverse opinions on the role of urbanization as a determinant of ecological footprint, studies on this issue is considered to lack consensus. Consistent with these concerns, the present study proposes that:

Proposition 3: Urbanization influences ecological footprint.

\section{Conclusion}

This paper has discussed the linkages between ecological footprint and urbanization toward health expenditure conceptually. Based on the discussion, this paper proposes three fundamental propositions in which urbanization, ecological footprint, and public health expenditure play a pivotal role in fostering economic prosperity and environmental sustainability. The first proposition is that ecological footprint influences public health expenditure. It is supported by previous studies that show a positive relationship between these variables, indicate that it is imperative to mitigate negative health impacts of environmental degradations. Among others, it is suggested that implementing carbon-reducing policy measurements such as carbon pricing mechanisms and energy efficiency measures can effectively reduce health spending on pollution-related ailments. Green technology should also be encouraged to achieve low carbon economies, greater energy security, and a cleaner environment.

The second proposition is the urbanization influences health expenditure. This proposition emphasizes that urbanization plays an essential element in determining health expenditure. Unorganized, unplanned, rapid, and over increased urban growth may induce environmental problems, naturally stimulating higher health costs. Thus, the government should redevelop and redesign the health policy frameworks, strategies, and plan that are more robust and effective, taking into account the urban sprawl. More health campaigns and education need to be effectively executed to achieve health equity. On the other hand, urbanization policies should include few measures such as higher investment in developing sustainable urban infrastructure 
and medical facilities and preventing excessive rural-urban migration by increasing cultivable land and income equalization.

The third proposition is that the ecological footprint influences urbanization. The positive relationship is supported by previous researchers, which indicates that growing urbanization leads to higher ecological footprints. Urbanization may lead to structural change in food, energy, and durable goods consumption patterns, which highly likely lead to undesirable effects on environments. Thus, urban sustainable consumption behavior is essential to alleviate climate change effects along with sustainable urban development. There is a pressing need to change urban lifestyles that are less damaging to the ecosystem and prevent the rapid spread of infectious diseases.

Many issues regarding urbanization, environmental problems, and health are not properly addressed due to the lack of data and funding. The existing studies, particularly in the theoretical development, have been few and far between. Therefore, the novel research at regional, national, local, and community levels are crucial so a holistic approach to environmental issues can be developed.

\section{Theoretical and Contextual Contribution}

This paper would significantly contribute to theory and practice because, theoretically, it would enhance the existing literature, so the existing gap in the literature about the association of ecological footprint and urbanization towards health expenditure would be fulfilled. In this paper, the independent variable used, namely ecological footprint, was new and not yet used by other researchers towards the dependent variable of health expenditure. Practically, this research would assist a country in determining the role of environmental pollution and urbanization in deciding their health expenditure. Eventually, the government would be able to frame policies accordingly. We believe the government can support urban planning for beneficial activities and safety, enhance urban living conditions for everybody, including appropriate shelter and sanitation, and make urban areas more resilient to catastrophes and disasters. The strategic plan can guarantee that, as suggested by the SDG, urban sustainability and a healthy environment are effectively implemented for the benefit of future generations by 2050 .

\section{Suggestion for Future Research}

There were also some limitations in this study that should be addressed in the future. The current research focused solely on conceptual findings. Future research may use empirical evidence to support the framework presented, allowing both to be implemented for knowledge improvement. Furthermore, because the current findings were addressed in general, academics should do a study on a country or region so that the impact is more focused and beneficial. Furthermore, the research might be expanded by include factors linked to monetary policy, fiscal policy, and any government-controlled variables like political stability, corruption, interest rate, and others. 
INTERNATIONAL JOURNAL OF ACADEMIC RESEARCH ECONOMICS AND MANAGEMENT SCIENCES

Vol. 10 , No. 4, 2020, E-ISSN: 2226-3624 ㄷ 2020 HRMARS

\section{Acknowledgements}

This project is financially supported by the Dana Lestari Khas 2020 with the project code: 600TNCPI 5/3/DDN (06) (P9012/2020) from Universiti Teknologi MARA Cawangan Pahang.

\section{References}

Abdullah, H., Azam, M., \& Zakariya, S. K. (2016). The Impact of Environmental Quality on Public Health Expenditure in Malaysia. Asia Pacific Journal of Advanced Business and Social Studies, 2(2), 365-379.

Ahmed, Z., Zafar, M. W., \& Ali, S. (2020). Linking urbanization, human capital, and the ecological footprint in G7 countries: an empirical analysis. Sustainable Cities and Society, 55, 102064.

Alimi, O. Y., Ajide, K. B., \& Isola, W. A. (2020). Environmental quality and health expenditure in ECOWAS. Environment, Development and Sustainability, 22(6), 5105-5127.

Al-Mulali, U., Fereidouni, H. G., Lee, J. Y. M., \& Sab, C. N. B. C. (2013). Exploring the relationship between urbanization, energy consumption, and $\mathrm{CO} 2$ emission in MENA countries. Renewable and Sustainable Energy Reviews, 23, 107-112. https://doi.org/10.1016/j.rser.2013.02.041.

Apergis, Nicholas; Bhattacharya, Mita; Hadhri, W. (2021). Health care expenditure and environmental pollution: a cross-country comparison across different income groups. Environmental Science and Pollution Research, 27, 8142-8156.

Berman, J. D., Ebisu, K., Peng, R. D., Dominici, F., \& Bell, M. L. (2017). Articles Drought and the risk of hospital admissions and mortality in older adults in Western USA from 2000 to 2013 : a retrospective study. Lancet Planet Health, 1(1), e17-e25. https://doi.org/10.1016/S25425196(17)30002-5

Boachie, M. K., Mensah, I. O., Sobiesuo, P., Immurana, M., \& Iddrisu, A. (2014). Determinants of Public Health Expenditure in Ghana: A Cointegration Determinants of Public Health Expenditure in Ghana: A Cointegration Analysis. December 2016. https://doi.org/10.12691/jbe-2-2-1

Boachie, M. K., \& Ramu, K. (2017). Public Health Expenditure and Health Outcomes : A Review. $6(1), 15-21$.

Cai Y, Sam CY, Chang T. (2018). Nexus between clean energy consumption, economic growth, and CO2 emissions. J Clean Prod. 182:1001-11. DOI: 10.1016/j.jclepro.2018.02.035

Çetin, M. A., \& Bakirtaş, İ. (2019). Does Urbanization Induce the Health Expenditures? A Dynamic Macro-Panel Analysis for Developing Countries. Dumlupınar Üniversitesi Sosyal Bilimler Dergisi, 61, 208-222.

Charfeddine, L., \& Mrabet, Z. (2017). The impact of economic development and social-political factors on ecological footprint: A panel data analysis for 15 MENA countries. Renewable and Sustainable Energy Reviews, 76, 138-154.

Chen, Y., Ebenstein, A., Greenstone, M., \& Li, H. (2013). Evidence on the impact of sustained exposure to air pollution on life expectancy from China's Huai River policy. Proceedings of the National Academy of Sciences, 110(32), 12936-12941.

City, B. L., \& Assessment, E. (2010). Urbanization and health. Bulletin of the World Health Organization, 88(4), 245-6. 
Danish, Hassan, S. T., Baloch, M. A., Mahmood, N., \& Zhang, J. (2019). Linking economic growth and ecological footprint through human capital and biocapacity. Sustainable Cities and Society101516. https://doi.org/10.1016/j.scs.2019.101516.

Danish, \& Wang, Z. (2019). Investigation of the ecological footprints driving factors: What we learn from the experience of emerging economies. Sustainable Cities and Society 101626. https://doi.org/10.1016/j.scs.2019.101626.

Eneji, M. A., Juliana, D. V., \& Onabe, B. J. (2013). Health care expenditure, health status and national productivity in Nigeria ( 1999-2012 ). 5(7), 258-272. https://doi.org/10.5897/JEIF2013.0523

Fattahi, M. (2015). The role of urbanization rate in the relationship between air pollution and health expenditures : a dynamic panel data approach Maryam Fattahi. International Letters $\begin{array}{llll}\text { of Social } \text { and } & \text { Humanistic }\end{array}$ https://doi.org/10.18052/www.scipress.com/ILSHS.53.68

Gbesemete, K. P., \& Gerdtham, U. G. (1992). Determinants of health care expenditure in Africa: a cross-sectional study. World Development, 20(2), 303-308.

Geng, L., Wu, Z., Zhang, S., \& Zhou, K. (2019). The end effect in air pollution: The role of perceived difference. Journal of Environmental Management, 232,413-420.

GFN (2018). Global footprint network. Retrieved from http://data.footprintnetwork.org/\#/countryTrends?type=BCtot,EFCtot\&cn=165.

Gillani, D. Q., Ahmad, S., Gillani, S., Naeem, M. Z., Spulbar, C., Coker-farrell, E., Ejaz, A., \& Birau, R. (2021). The Nexus between Sustainable Economic Development and Government Health Expenditure in Asian Countries Based on Ecological Footprint Consumption.

Hardy, V. P., Shaheen, A., \& Milojevic, A. (2019). Modification of the impact of access to water on childhood diarrhoea by socioeconomic status in the Gaza Strip from 2000 to 2014: a crosssectional study. The Lancet, 393, S29.

Heyes, A., \& Zhu, M. (2019). Air pollution as a cause of sleeplessness: Social media evidence from a panel of Chinese cities. Journal of Environmental Economics and Management, 98, 102247.

Huang, L., Wu, J., \& Yan, L. (2015). Defining and measuring urban sustainability : a review of indicators. Landscape Ecology, 30(7), 1175-1193. https://doi.org/10.1007/s10980-0150208-2

Huber, M., \& Orosz, E. (2003). Health Expenditure Trends in OECD Countries, 1990-2001. 25(1), 1990-2001.

Ibukun, C. O., \& Osinubi, T. T. (2020). Environmental quality, economic growth, and health expenditure: empirical evidence from a panel of African countries. African Journal of Economic Review, 8(2), 119-140.

Kim, T. K. \& L. S. R. (2013). Government Health Expenditure and Public Health Outcomes : A Comparative Study among 17 Countries and Implications for US Health Care Reform Tae Kuen Kim, PhD Adelphi University School of Social Work Adelphi University School of Social Work. 3(9), 8-13.

Kissinger, M., Sussman, C., Moore, J., \& Rees, W. E. (2013). Consumer Goods at the Urban Scale. 1960-1973. https://doi.org/10.3390/su5051960

Kouassi, E., Akinkugbe, O., Kutlo, N. O., \& Brou, J. B. (2018). Health expenditure and growth dynamics in the SADC region: Evidence from non-stationary panel data with cross section 
INTERNATIONAL JOURNAL OF ACADEMIC RESEARCH ECONOMICS AND MANAGEMENT SCIENCES

Vol. 10, No. 4, 2020, E-ISSN: 2226-3624 @ 2020 HRMARS

dependence and unobserved heterogeneity. International Journal of Health Economics and Management, 18(1), 47-66.

Khan, I., Hou, F., Le, H. P., \& Ali, S. A. (2021). Do natural resources, urbanization, and value-adding manufacturing affect environmental quality? Evidence from the top ten manufacturing countries. Resources Policy, 72, 102109.

Lee, Y. J., \& Lin, S. Y. (2020). Vulnerability and ecological footprint: a comparison between urban Taipei and rural Yunlin, Taiwan. Environmental Science and Pollution Research, 27(28), 34624-34637.

Lenzen, M., Malik, A., Li, M., Fry, J., Weisz, H., Pichler, P., Suveges, L., Chaves, M., Capon, A., \& Pencheon, D. (2020). Articles The environmental footprint of health care: a global assessment. The Lancet Planetary Health, 4(7), e271-e279. https://doi.org/10.1016/S2542-5196(20)30121-2

Li, D. Z., Hui, E. C., Leung, B. Y., Li, Q. M., \& Xu, X. (2010). A methodology for eco-efficiency evaluation of residential development at city level. Building and Environment, 45(3), 566573.

Lu, Y., \& Chen, B. (2017). Urban ecological footprint prediction based on the Markov chain. 163, 146-153. https://doi.org/10.1016/j.jclepro.2016.03.034

Magazzino, C., \& Mele, M. (2012). The Determinants of Health Expenditure in Italian Regions. May 2014. https://doi.org/10.5539/ijef.v4n3p61

Magazzino, C., Mele, M., \& Schneider, N. (2020). The relationship between municipal solid waste and greenhouse gas emissions : Evidence from Switzerland. Waste Management, 113, 508520. https://doi.org/10.1016/j.wasman.2020.05.033

Mahmood, H., Alkhateeb, T. T. Y., \& Furqan, M. (2020). Oil sector and CO 2 emissions in Saudi Arabia: asymmetry analysis. Palgrave Communications, 6(1), 1-10.

Mallett, L. H., \& Etzel, R. A. (2018). Flooding: what is the impact on pregnancy and child health? Disasters, 42(3), 432-458.

Mehrara, M.; Sharzei, G.; Mohaghegh, M. (2011). The Relationship between Health Expenditure and Environmental Quality in Developing Countries. J. Health Adm. 14, 79-88.

Mohd Arshad, A., \& Khan, N. A. (2021). Decomposing the trade-environment nexus for high income, upper and lower middle income countries: What do the composition, scale, and technique effect indicate? Ecological Indicators, 121(May 2020), 107122. https://doi.org/10.1016/j.ecolind.2020.107122

Nathaniel, S., Abdul, S., \& Khan, R. (2020). The nexus between urbanization, renewable energy , trade, and ecological footprint in ASEAN countries. Journal of Cleaner Production, 272, 122709. https://doi.org/10.1016/j.jclepro.2020.122709

Pan, J., \& Liu, G. G. (2012). The determinants of Chinese provincial government health expenditures: evidence from 2002-2006 data. Health economics, 21(7), 757-777.

Pata UK. (2018). Renewable energy consumption, urbanization, financial development, income and $\mathrm{CO} 2$ emissions in Turkey: testing EKC hypothesis with structural breaks. J Clean Prod. 187:770-9. doi: 10.1016/j.jclepro.2018.03.236

Patil, R. R. (2014). Urbanization as a determinant of health: a socio epidemiological perspective. Social work in public health, 29(4), 335-341.

Rahman, M. (2011). Causal Relationship among Education Expenditure, Health Expenditure and GDP : A Case Study for Bangladesh. 3(3), 149-159. 
Qaiser, G., Tariq, S., Adnan, S., \& Latif, M. (2021). Evaluation of a composite drought index to identify seasonal drought and its associated atmospheric dynamics in Northern Punjab, Pakistan. Journal of Arid Environments, 185, 104332.

Rahman, M. M., Khanam, R., \& Rahman, M. (2019). Health care expenditure and health outcome nexus : new evidence from the SAARC-ASEAN region. 2018, 1-11.

Ramírez-chaves, H. E., Noguera-urbano, E. A., Morales-martínez, D. M., Zurc, D., Vargas-arboleda, A. F., Mantilla-meluk, H., \& Salcedo-reyes, J. C. (2020). Endemic bats ( Mammalia: Chiroptera ) of Colombia : State of knowledge, distribution, and conservation. 25(1), 5594. https://doi.org/10.11144/Javeriana.SC25-1.ebmc

Rashid, A., Irum, A., Malik, I. A., Ashraf, A., Rongqiong, L., Liu, G., ... \& Yousaf, B. (2018). Ecological footprint of Rawalpindi; Pakistan's first footprint analysis from urbanization perspective. Journal of Cleaner Production, 170, 362-368.

Rogers, D. S., Duraiappah, A. K., Antons, D. C., Munoz, P., Bai, X., Fragkias, M., \& Gutscher, H. (2012). A vision for human well-being: transition to social sustainability. Current Opinion in Environmental Sustainability, 4(1), 61-73.

Shen, J., Wang, Q., \& Shen, H. (2021). Does Industrial Air Pollution Increase Health Care Expenditure ? Evidence From China. 9(June), 1-9.

https://doi.org/10.3389/fpubh.2021.695664

Shi, L., Smit, E., \& Luck, J. (2021). Panel Survey Estimation of the Impact of Urbanization in China: Does Level of Urbanization Affect Healthcare Expenditure, Utilization or Healthcare Seeking Behavior?. The Chinese Economy, 54(3), 145-156.

Shultz, J. M., Shepherd, J. M., Kelman, I., Rechkemmer, A., \& Galea, S. (2017). Comment Mitigating tropical cyclone risks and health consequences : urgencies and innovations. The Lancet Planetary Health, 2(3), e103-e104. https://doi.org/10.1016/S2542-5196(18)300214

Stanaway, J. D., Reiner, R. C., Blacker, B. F., Goldberg, E. M., Khalil, I. A., Troeger, C. E., \&, \& Hay, S. I. (2017). Articles The global burden of typhoid and paratyphoid fevers : a systematic analysis for the Global Burden of Disease Study 2017. The Lancet Infectious Diseases, 19(4), 369-381. https://doi.org/10.1016/S1473-3099(18)30685-6

UN Habitat. (2020). World Cities Report 2020: The value of sustainable urbanization. UN Habitat. https://unhabitat.org/World Cities Report 2020

United Nations Environment Program, (2016). UNEP Environment for development, urban environment unit.

http://www.unep.org/urban_environment/Issues/urban_air.asp4/3/2016

Vaccari, M., Vinti, G., Cesaro, A., Belgiorno, V., Salhofer, S., Dias, M. I., \& Jandric, A. (2019). WEEE treatment in developing countries: Environmental pollution and health consequences - An overview. International journal of environmental research and public health, 16(9), 1595.

Wang, C. M., Hsueh, H. P., Li, F., \& Wu, C. F. (2019). Bootstrap ARDL on health expenditure, CO2 emissions, and GDP growth relationship for 18 OECD countries. Frontiers in public health, 7, 324.

Watts, N., Amann, M., Arnell, N., Ayeb-Karlsson, S., Belesova, K., Byass, P., Cai, W., Campbelllendrum, D., Capstick, S., Dubrow, R., Ebi, K. L., Eckelman, M., Ekins, P., Escobar, L. E., Fernandez, L., Georgeson, L., Graham, H., Haggar, P., Hamilton, I., ... Wilkinson, P. (2019). The 2019 Report of The Lancet Countdown on Health and Climate Change. 1-105. 
Wei, Y., Gu, J., Wang, H., Yao, T., \& Wu, Z. (2018). Uncovering the culprits of air pollution : Evidence from China' s economic sectors and regional heterogeneities. Journal of Cleaner Production, 171, 1481-1493. https://doi.org/10.1016/j.jclepro.2017.09.246

World Health Organization. (2011). Global status report on noncommunicable diseases 2010. https://www.who.int/nmh/publications/ncd_report_full_en.pdf

Wu, J. (2010). Urban sustainability: an inevitable goal of landscape research. https://doi.org/10.1007/s10980-009-9444-7

Yang, B., Usman, M., \& Jahanger, A. (2021). Do industrialization, economic growth and globalization processes influence the ecological footprint and healthcare expenditures? Fresh insights based on the STIRPAT model for countries with the highest healthcare expenditures. Sustainable Production and Consumption, 28, 893-910.

Yazdi, S. K., \& Tahmasebi, Z. (2014). Public Healthcare Expenditure and Environmental quality in Iran Public Healthcare Expenditure and Environmental quality in Iran. Recent Advances in Applied Economics, 1(October 2014), 126-134.

Yin, C. L., Meng, F., Xu, Y. N., Yang, X. Y., Xing, H. Q., \& Fu, P. J. (2020). Infrared Physics \& Technology Developing urban built-up area extraction method based on land surface emissivity differences. 110(June). https://doi.org/10.1016/j.infrared.2020.103475

Zaidi, S., \& Saidi, K. (2018). Environmental Pollution, Health Expenditure and Economic growth in the Sub-Saharan Africa countries: Panel ARDL approach. Sustainable Cities and Society, 41(May), 833-840. https://doi.org/10.1016/j.scs.2018.04.034

Zeng, C., Deng, X., Dong, J., \& Hu, P. (2016). Urbanization and sustainability: comparison of the processes in "BIC" countries. Sustainability, 8(4), 400.

Zerbo, A., Delgado, R. C., \& González, P. A. (2020). A review of the risk of cholera outbreaks and urbanization in sub-Saharan Africa. Journal of Biosafety and Biosecurity, 2(2), 71-76. https://doi.org/10.1016/j.jobb.2020.11.004

Zhang L., Ju MT, Q. Z. L. (2011). Ecological footprint of energy consumption and its management in Tianjin. . Journal of Safety and Environment, 11(3), 142-147. 